\title{
Purvalanol induces endoplasmic reticulum stress-mediated apoptosis and autophagy in a time-dependent manner in HCT116 colon cancer cells
}

\author{
AJDA COKER-GÜRKAN, ELIF DAMLA ARISAN, PINAR OBAKAN, KÜBRAAKALIN*, \\ UTKU ÖZBEY* and NARCIN PALAVAN-UNSAL \\ Department of Molecular Biology and Genetics, Science and Letters Faculty, Istanbul Kultur University, \\ Atakoy Campus, Bakirkoy-Istanbul 34156, Turkey
}

Received August 3, 2014; Accepted December 18, 2014

DOI: $10.3892 /$ or.2015.3918

\begin{abstract}
Purvalanol, a novel cyclin-dependent kinase inhibitor, is referred to as a strong apoptotic inducer which causes cell cycle arrest in various cancer cells such as prostate, breast and colon cancer cell lines. Various physiological and pathological conditions such as glucose starvation, inhibition of protein glycosylation and oxidative stress may cause an accumulation of unfolded proteins in the endoplasmic reticulum (ER), leading to the unfolded protein response (UPR) and autophagy. Lacking proteosomal function on aggregates of unfolded proteins, ER stress may induce autophagic machinery. Autophagy, an evolutionarily conserved process, is characterized by massive degradation of cytosolic contents. In the present study, our aim was to determine the timedependent, ER-mediated apoptotic and autophagy induction
\end{abstract}

Correspondence to: $\mathrm{Dr}$ Ajda Coker-Gürkan, Department of Molecular Biology and Genetics, Science and Letters Faculty, Istanbul Kultur University, Atakoy Campus, Bakirkoy-Istanbul 34156, Turkey E-mail: a.coker@iku.edu.tr

*Contributed equally

Abbrevations: ABTS, 2,2'-azino-di-[3-ethylbenzthiazoline sulfonate (6)] diammonium salt; ATF-6, activating transcription factor-6; CDK, cyclin-dependent kinase; CDKI, cyclin-dependent kinase inhibitor; CHOP, CAAT/enhancer-binding protein; DiOC6, 3,3'-dihexyloxacarbocyanine iodide; DMSO, dimethyl sulfoxide; ER, endoplasmic reticulum; GFP, green fluorescent protein; HRP, horseradish peroxidase; IRE1, inositol-requiring enzyme 1; JNK, c-Jun N-terminal kinase; LC3, microtubule-associated protein 1A/1B-light chain 3; MMP, mitochondrial membrane potential; MTT, 3-4,5-dimethyl-2thiazolyl-2,5-diphenyl-2H-tetrazolium bromide; UPR, unfolded protein response; PERK, PRKR-like ER kinase; PBS, phosphatebuffered saline; PI, propidium iodide; POD, peroxidase; PVDF, polyvinyldifluoride; $\mathrm{Rb}$, retinoblastoma; SDS-PAGE, sodium dodecyl sulphate polyacrylamide gel electrophoresis; TBS, Tris-buffered saline; XBP-1, X-box binding protein 1

Key words: purvalanol, endoplasmic reticulum stress, autophagy, apoptosis, colon cancer of purvalanol in HCT 116 colon cancer cells. Fifteen micromoles of purvalanol induced a reduction in cell viability by 20 and $35 \%$ within 24 and 48 h, respectively. HCT 116 colon cancer cells were exposed to purvalanol, which activated ER stress via upregulation of PERK, IRE1 $\alpha$ gene expression, eIF- $2 \alpha$ phosphorylation and ATF- 6 cleavage at early time-points in the HCT 116 colon cancer cells. Moreover, we determined that during purvalanol-mediated ER stress, autophagic machinery was also activated prior to apoptotic cell death finalization. Beclin-1 and Atg-5 expression levels were upregulated and LC3 was cleaved after a $6 \mathrm{~h}$ purvalanol treatment. Purvalanol induced mitochondrial membrane potential loss, caspase-7 and caspase- 3 activation and PARP cleavage following a $48 \mathrm{~h}$ treatment. Thus, we conclude that the anticancer effect of purvalanol in HCT 116 cells was due to ER stress-mediated apoptosis; however, purvalanol triggered autophagy, which functions as a cell survival mechanism at early time-points.

\section{Introduction}

Cyclin-dependent kinases (CDKs), are members of the serine-threonine protein kinase family and are responsible for taking control of cell cycle regulation in eukaryotic cells. CDKs show their action by interacting with cyclins and different CDK-cyclin complexes regulate the cell cycle in the G1, S and G2/M phases (1). New anticancer therapy strategies refer to the inhibition of CDK-cyclin complexes as an important target to prevent uncontrolled proliferation and induce apoptosis in cancer cells (2). Olomoucine, roscovitine and purvalanol are examples of CDK inhibitors (CDKIs) designed and investigated for their apoptotic potential on cancer cells (3). Purvalanol is a purine-derived CDKI that binds with a high selectivity and competitively to the ATP binding side of CDK1/2 and leads to $\mathrm{G} 2 / \mathrm{M}$ cell cycle arrest (4). Their impact on the apoptotic cell death mechanism requires further elucidation. Natural polyamines, putrescine, spermidine and spermine, play essential roles in the regulation of cell growth and proliferation. Increased levels of polyamines in cells are considered to be involved in cancer progression. Intracellular polyamine levels are under the control of several catabolic enzymes, such as 
spermidine/spermine-N-acetyl transferase (SSAT). Although purvalanol-induced cell cycle arrest and apoptotic cell death were demonstrated in prostate (5), breast (6) and colon cancer cells (7), the exact molecular mechanism of purvanol-induced apoptosis has not been elucidated yet.

Endoplasmic reticulum (ER) is an essential organelle responsible for protein synthesis, folding, post-translational modification of proteins and protein trafficking in eukaryotes (8). ER alerts a self-protective mechanism that is called ER stress during nutrient deprivation, pathogen infection, alterations in redox status, intraluminal $\mathrm{Ca}^{2+}$ levels and folding defective protein conditions (9). ER stress response is initiated by activation of three types of ER membrane receptors; inositol-requiring enzyme 1 (IRE1 $\alpha$ ), PRKR-like ER kinase (PERK) and activating transcription factor-6 (ATF-6). Activated and released IRE1 $\alpha$ acts as an RNase to initiate transcription of XBP1 mRNA and it becomes a transcriptional activator for unfolded protein response (UPR) gene targets, such as BiP and calreticulin (10). Activation of ER membrane receptor PERK, during prolonged UPR, phosphorylates eIF2 $\alpha$ to attenuate mRNA transcription within the cell (11). Recently, autophagy, a cytoprotective intracellular degradation system, is assumed to be activated by both IRE1 $\alpha$ and PERK as an alternative way to degrade accumulated misfolded proteins (12). Concominantly, during UPR stress, ATF-6 is released from $\mathrm{BiP}$ and translocates from the ER to the Golgi. Cleaved ATF-6 migrates to the nucleus and transactivates various chaperones and major ER stress markers such as the CAAT-enhancer binding protein $(\mathrm{CHOP})$ gene. $\mathrm{CHOP}$ is a transcription factor that regulates the expression of the Bcl-2 family members. Overexpression of CHOP induces apoptosis and its deficiency has been shown to protect cells from apoptotic cell death. Prolonged severe ER stress could eventually activate caspase-12 and caspase-dependent apoptosis (13). Thus, our aim in the present study was to understand the molecular basis of purvalanol-induced ER stress which leads to cell death in HCT 116 colon cancer cells.

\section{Materials and methods}

Drugs and antibodies. Purvalanol was purchased from Tocris Bioscience (Bristol, UK), dissolved in DMSO to make a $10 \mathrm{mM}$ stock solution and stored at $-20^{\circ} \mathrm{C}$. Phospho-Rb, p53, p21, Bad, Bid, Bik, PUMA, Mcl-1, Bcl-xL, pro-caspase-3, procaspase-7, PARP, Beclin-1, p62, LC3, Atg-5, Atg-12, PERK, XBP1, caspase-12, JNK, ATF-6, CHOP, BiP, IRE1 $\alpha$, calnexin, calreticulin, PDI, c-jun, GAPDH and $\beta$-actin (each diluted 1:1,000) rabbit antibodies were purchased from Cell Signaling Technology (CST, Danvers, MA, USA). HRP-conjugated secondary anti-rabbit antibodies (diluted 1:3,000) were from CST.

Cell culture. HCT 116 colon cancer cells (CCL 247) were purchased from the American Type Culture Collection (ATCC, Manassas, VA, USA). Cells were maintained in McCoy's 5A medium (Gibco, Invitrogen, Carlsbad, CA, USA) with 10\% fetal bovine serum (Pan Biotech, Aidenbach, Germany) and $100 \mathrm{U} / 100 \mathrm{mg} / \mathrm{ml}$ penicilin/streptomycin and grown in the presence of $5 \% \mathrm{CO}_{2}$ in humidified air at $37^{\circ} \mathrm{C}$ (Heracell 150; Thermo Electron Corporation, Waltham, MA, USA).
Cell viability assay. The effects of purvalanol on cell viability were determined by colorimetric 3-(4,5-dimethylthiazol-2-yl)-2,5-diphenyl-tetrazolium bromide (MTT; Roche, Indianapolis, IN, USA) assay. Cells were seeded at a density of $1 \times 10^{4}$ cells/well in 96-well plates, allowed to attach overnight and treated for 24 and $48 \mathrm{~h}$ with various concentrations of purvalanol $(0-30 \mu \mathrm{M})$. After purvalanol treatment, $10 \mu \mathrm{l}$ of MTT reagent $(5 \mathrm{mg} / \mathrm{ml})$ was added to the cell culture medium for $4 \mathrm{~h}$. Following removal of media, $200 \mu \mathrm{l}$ DMSO was added to dissolve the formazan crystals, which are produced due to activated mitochondria. The absorbance of the suspensions was determined at $570 \mathrm{~nm}$ with a microplate reader (Bio-Rad, Hercules, CA, USA).

Trypan blue dye exclusion assay. Cells were seeded on 6-well plates $\left(5 \times 10^{4}\right.$ cells/well) and treated with purvalanol $(15 \mu \mathrm{M})$ for $96 \mathrm{~h}$. Every $24 \mathrm{~h}$, the cells were trypsinized and stained with trypan blue and viable and dead cells were counted under light microscopy. Data were platted on a graph indicating the number of cells (y-axis) vs. time (x-axis).

\section{Fluorescence microscopy}

PI staining. HCT 116 cells $\left(1 \times 10^{5}\right)$ were seeded into 12-well plates and treated with purvalanol $(0-30 \mu \mathrm{M})$ for $24 \mathrm{~h}$. Following a dose-dependent purvalanol treatment, the cells were washed once with 1X PBS and stained with propidium iodide (PI) $(50 \mathrm{mg} / \mathrm{ml}$ stock concentration in 1X PBS) fluorescent probe and were incubated for $10 \mathrm{~min}$ in the dark. Purvalanol-induced cell death was detected with fluorescence microscopy (Olympus, Tokyo, Japan).

DAPI staining. The cells were seeded in 12 -well plates at a density of $1 \times 10^{5}$ cells/well and treated with purvalanol $(0-30 \mu \mathrm{M})$ for $24 \mathrm{~h}$. After treatment, the cells were washed once with 1X PBS. The cells were stained with $1 \mu \mathrm{l} / \mathrm{ml}$ 4',6-diamidino-2-phenylindole (DAPI) $(1 \mathrm{mg} / \mathrm{ml}$ stock concentration in 1X PBS) fluorescent probe and were incubated for $10 \mathrm{~min}$ in the dark. Dose-dependent purvalanol-induced nuclear DNA fragmentation was visualized using fluorescence microscopy.

DiOC6 staining. HCT $116\left(1 \times 10^{5}\right)$ cells were seeded into 12 -well plates. Following exposure of cells to purvalanol $(0-30 \mu \mathrm{M})$, they were washed once with $1 \mathrm{XPBS}$, and then stained with $4 \mathrm{nM} \mathrm{3,3'-dihexyloxacarbocyanine} \mathrm{iodide} \mathrm{[DiOC6(3)]}$ (40 nM stock concentration in DMSO; Calbiochem, La Jolla, CA, USA) fluorescent probe. Mitochondrial membrane potential (MMP) disruption was visualized by fluorescence microscopy.

Cell cycle analysis by PI staining. HCT 116 colon carcinoma cells at a density of $2 \times 10^{5}$ cells/well were seeded in 6-well plates, and then subsequently treated with purvalanol $(15 \mu \mathrm{M})$ for 12, 24 and $48 \mathrm{~h}$. Both floating and adherent cells were collected and fixed with 70\% ethanol. Following incubation on ice for $30 \mathrm{~min}$, the cells were diluted with 1X PBS. Samples were then centrifuged at 1,200 rpm for $5 \mathrm{~min}$. Pellets were resuspended in $1 \mathrm{X}$ PBS, RNase $(100 \mu \mathrm{g} / \mathrm{ml})$ and PI solution $(40 \mu \mathrm{g} / \mathrm{ml})$. Samples were kept for $30 \mathrm{~min}$ at $37^{\circ} \mathrm{C}$ in the dark. Cell cycle distribution was analyzed by Accuri C6 (BD Biosciences, Oxford,UK). 10,000 events/sample were acquired and evaluated using BD Accuri C6 software (BD Biosciences). 
CHOP activation by FACS flow analysis. HCT 116 colon carcinoma cells were seeded in 6-well plates and transfected with CHOP promoter $(-649 /+136)$ pmCherry-1 plasmid $(0.5 \mathrm{mg} /$ $\mathrm{ml}$ ) using the Fugene6 (Promega, Sunnyvale, CA, USA). After a $24 \mathrm{~h}$ transfection, the cells were exposed to purvalanol $(15 \mu \mathrm{M})$ for 12,24 and $48 \mathrm{~h}$. Following purvalanol treatment, mCherry-CHOP plasmid-transfected 10,000 cells/sample were determined by flow cytometry using FL-3 (red fluorescence) (FACScan, Attune; Applied Biosciences, Foster City, CA, USA).

GFP-LC3 localization by FACS flow analysis. HCT 116 colon carcinoma cells were seeded in 6-well plates and transfected with a green fluorescent protein (GFP)-tagged LC3-expressing vector $(0.5 \mu / \mathrm{ml})$ using Fugene6. After a $24 \mathrm{~h}$ transfection, the cells were exposed to purvalanol $(15 \mu \mathrm{M})$ for 12,24 and $48 \mathrm{~h}$. Following purvalanol treatment, GFP-LC3 plasmidtransfected 10,000 cells/sample were determined by flow cytometry using FL-1 (green fluorescence) (FACScan, Attune; Applied Biosciences).

Cell death ELISA assay. HCT 116 cells $\left(1 \times 10^{4}\right)$ were seeded in 96-well plates and treated with $15 \mu \mathrm{M}$ purvalanol for 12,24 and $48 \mathrm{~h}$. Cytoplasmic histone-associated-DNA fragments (monoand oligonucleosomes) were determined using Cell Death Detection ELISA Plus assay, according to the manufacturer's instructions (Roche). Briefly, cell lysates were placed in a streptavidin-coated microplate. A mixture of anti-histone-biotin and anti-DNA-POD was added and incubated for $2 \mathrm{~h}$ at $15-25^{\circ} \mathrm{C}$. Following the removal of unbound antibodies by a washing procedure, POD was determined photometrically at $405 \mathrm{~nm}$ with 2,2'-azino-di-[3-ethylbenzthiazoline sulfonate (6)] diammonium salt (ABTS) as a substrate. In order to determine the DNA fragments following drug treatment in colon carcinoma cells, total DNA content was isolated.

Protein extraction and immunoblotting. HCT 116 colon carcinoma cells were treated with the appropriate concentrations of purvalanol in a time-dependent manner. First, all the samples were washed with ice-cold $1 \mathrm{X}$ PBS and lysed on ice in a solution containing $20 \mathrm{mM}$ Tris- $\mathrm{HCl}(\mathrm{pH} 7.5), 150 \mathrm{mM} \mathrm{NaCl}$, Nonidet P-40 0.5\%, (v/v), 1 mM EDTA, 0.5 mM PMSF, $1 \mathrm{mM}$ DTT and protease inhibitor cocktail (Complete, Roche). After cell lysis, the cell debris were removed by centrifugation for $15 \mathrm{~min}$ at 13,200 rpm, and protein concentrations were determined by the Bradford protein assay (BioRad). Total protein lysates $(30 \mu \mathrm{g})$ were separated on a $12 \%$ SDS-PAGE and transferred onto PVDF membranes (Roche). The membranes were then blocked with 5\% milk blocking solution in Tris buffer saline (TBS)-Tween 20 (Sigma) and incubated with appropriate primary and horseradish peroxidase (HRP)-conjugated secondary antibodies (CST) in antibody buffer containing 5\% (v/v) milk blocking solution. Following a gentle washing step with $1 \mathrm{X}$ TBS-Tween 20 , the proteins were analyzed using an enhanced chemiluminescence detection system (ECL). Bands were exposed to Lumi-Film Chemiluminescent Detection (Roche).

Statistical analysis. All the experiments were statistically analyzed by two-way ANOVA using GraphPad Prism 6
(GraphPad Software, La Jolla, CA, USA). Statistically significant results by ANOVA were further analyzed by Bonferroni post-hoc analysis (where indicated). A $\mathrm{p}<0.05$ was considered to indicate a statistically significant result. Error bars in the graphs were generated using \pm standard deviation (SD) values. Band intensities were quantified using ImageJ software and normalized to $\beta$-actin or GAPDH.

\section{Results}

Purvalanol inhibits cell viability and proliferation in a dose-dependent manner. In order to understand the time- and dose-dependent effects of purvalanol treatment on HCT 116 cell viability, we performed an MTT assay. According to the MTT assay, $15 \mu \mathrm{M}$ of purvalanol decreased the cell viability by $25 \%$ in HCT 116 cells within $24 \mathrm{~h}$. Exposure to purvalanol for $48 \mathrm{~h}$ decreased cell viability by $40 \%$ (Fig. 1A). Moreover, PI and DAPI staining of cells after dose-dependent purvalanol treatment for $24 \mathrm{~h}$ showed that cell death and nuclear condensation were increased in the HCT 116 colon cancer cells. In addition, we also determined that MMP disruption was increased in dose-dependent manner in the HCT 116 colon cancer cells (Fig. 1B). Cell survival analysis with trypan blue dye exclusion assay showed that $15 \mu \mathrm{M}$ purvalanol inhibited cell proliferation after $24 \mathrm{~h}$ and this cytostatic effect was maintained until $72 \mathrm{~h}$ (Fig. 1C).

Purvalanol induces cell cycle arrest in a time-dependent manner. The effect of purvalanol on the cell cycle profile of HCT 116 cells was examined following PI staining by FACS flow analysis. $15 \mu \mathrm{M}$ of purvalanol increased the subG1 population in a time-dependent manner $(12,24$ and $48 \mathrm{~h})$, to $1.7,2$ and $8.9 \%$, respectively (Fig. 2A). In order to confirm FACS flow analysis, we analyzed major cell cycle coordinating proteins such as phosphorylated Rb, p53 and p21 by immunoblotting. According to the immunoblotting results, purvalanol treatment increased the expression of p53 in a time-dependent manner, but significant upregulation was determined after a $48 \mathrm{~h}$ purvalanol treatment in the HCT 116 colon cancer cells. However, expression of p21 was increased only after a $24 \mathrm{~h}$ purvalanol treatment. Moreover, protein expression of the phosphorylated form of $\mathrm{Rb}$ (807/811) was sharply downregulated only after $12 \mathrm{~h}$ in HCT 116 colon cancer cells (Fig. 2B).

Purvalanol activates ER stress. In order to evalute the time-dependent effect of purvalanol on ER stress via activated $\mathrm{Ca}^{2+}$ metabolism, we performed immunoblotting. According to the immunblotting results, purvalanol upregulated both PDI and calnexin expression levels within $1 \mathrm{~h}$ of purvalanol exposure in the HCT 116 colon cancer cells. However, calreticulin, an ER resident protein with $\mathrm{Ca}^{2+}$ buffering effect, was downregulated in a time-dependent manner following $15 \mu \mathrm{M}$ of purvalanol treatment (Fig. 3A). We next examined the expression profiles of ER membrane proteins and their downstream target key molecules by immunoblotting. BiP expression was upregulated after a $3 \mathrm{~h}$ purvalanol treatment and this effect was increased in a time-dependent manner. Moreover, a $1 \mathrm{~h}$ purvalanol treatment induced PERK expression and phosphorylation of eIF-2 $\alpha$ within a $3 \mathrm{~h}$ drug exposure in the HCT 116 cells. Another ER membrane receptor, IRE1 $\alpha$, 

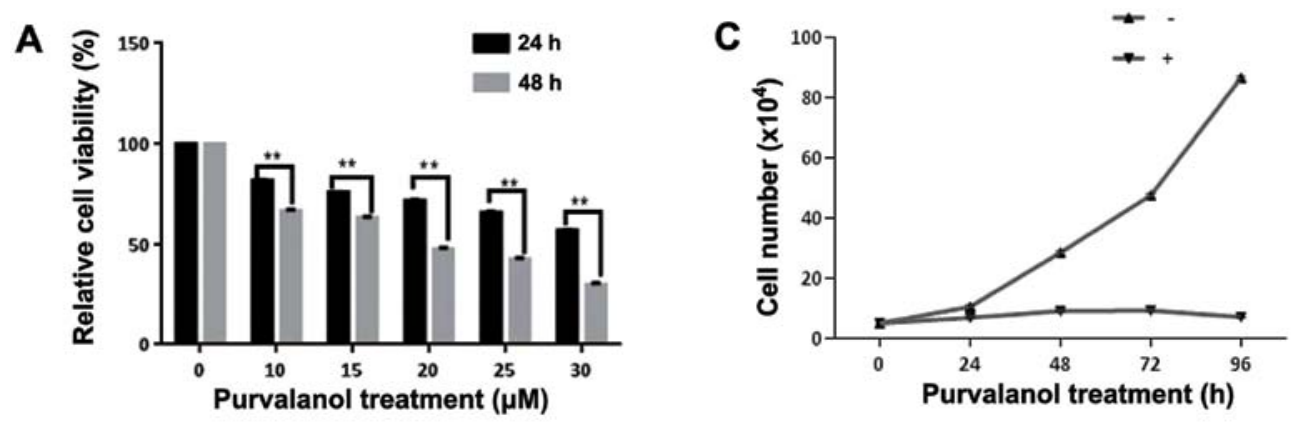

B

Purvalanol treatment $(\mu \mathrm{M})$
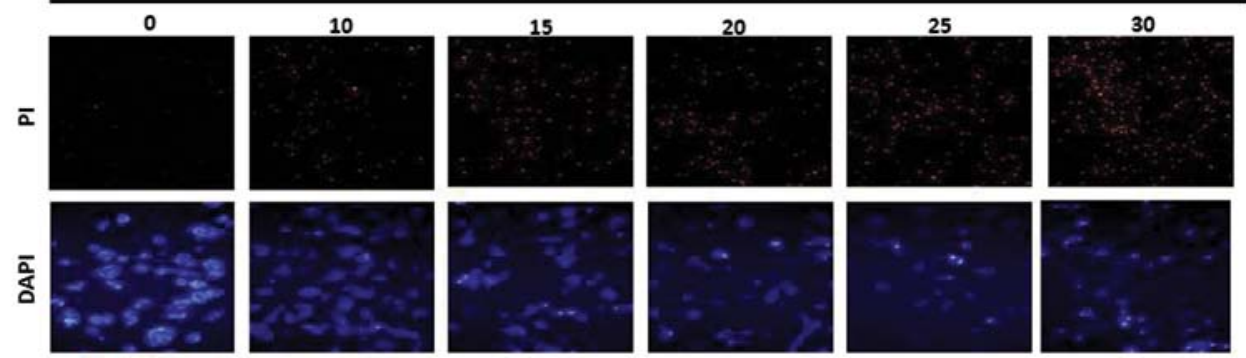

은
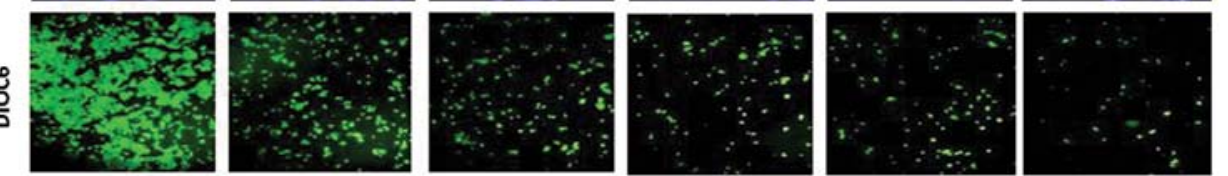

Figure 1. Purvalanol decreases cell viability, inhibits cell proliferation and induces cell death in a dose- and time-dependent manner in the HCT 116 colon cancer cells. (A) Cells were seeded into a 96-well plate and treated with purvalanol (0-30 $\mu \mathrm{M})$ for 24 and $48 \mathrm{~h}$. Cell viability was determined by an MTT assay. Values represent the mean \pm SD of three different experiments with at least three replicates. (B) Dose-dependent purvalanol effects on cell death and nuclear condensation were determined by PI, DAPI staining, respectively and the disruption of MMP was visualized by DiOC6 staining after a $24 \mathrm{~h}$ exposure of HCT 116 cells to $0-30 \mu \mathrm{M}$ purvalanol. (C) Cells were seeded into a 6-well plate and treated with purvalanol (15 $\mu \mathrm{M})$ for $24,48,72$ and $96 \mathrm{~h}$. Cell proliferation was determined by the trypan blue dye exclusion method. Values represent the mean \pm SD of three different experiments with at least three replicates. PI, propidium iodide.

\section{A Purvalanol treatment (h)}

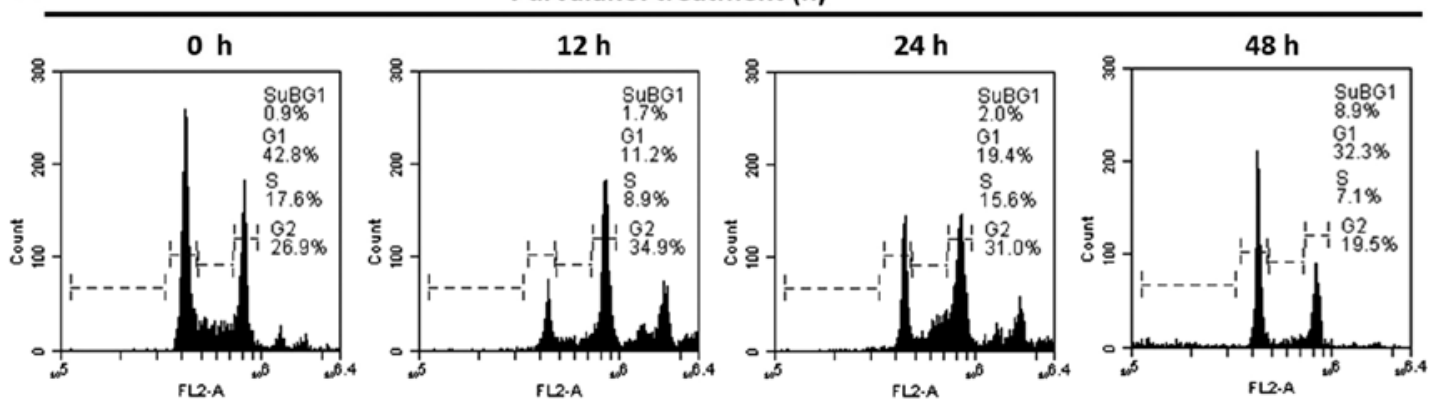

B

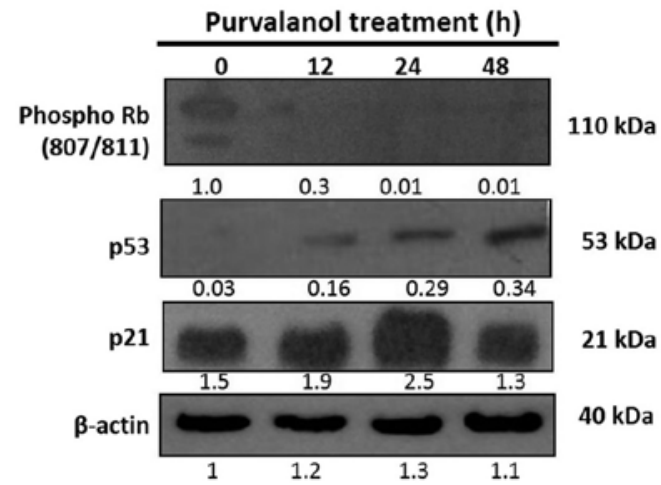

Figure 2. Effects of purvalanol on cell cycle progression. (A) HCT 116 cells were treated with $15 \mu \mathrm{M}$ purvalanol for 12,24 and $48 \mathrm{~h}$ and then the cells were harvested, fixed with ethanol and stained with PI. The cellular DNA contents were determined by flow cytometric analysis to detect the cell cycle distribution. Results shown are reprensentative of three independent experiments. (B) The effect of purvalanol treatments on the p53, p21 and the retinoblastoma (Rb) gene expression profiles are shown by the immunoblotting method. $\beta$-actin was used as a loading control. 
A

A

Purvalanol treatment (h)

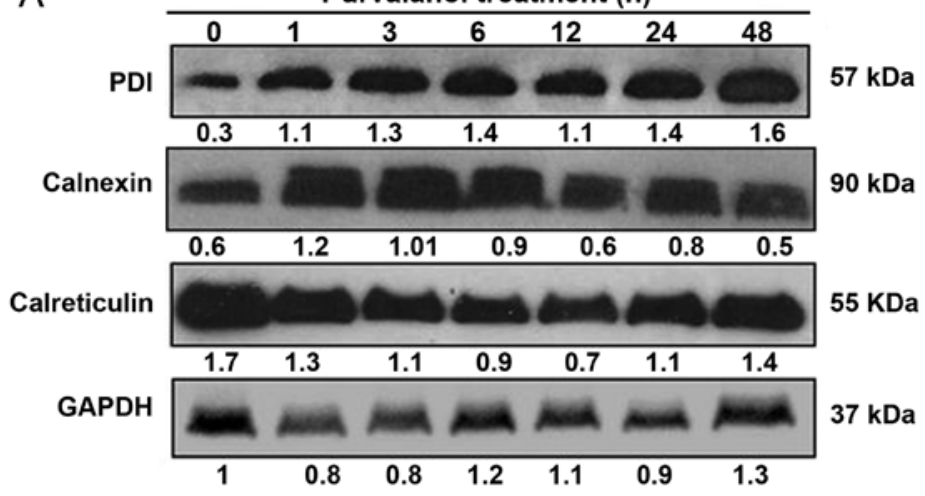

B

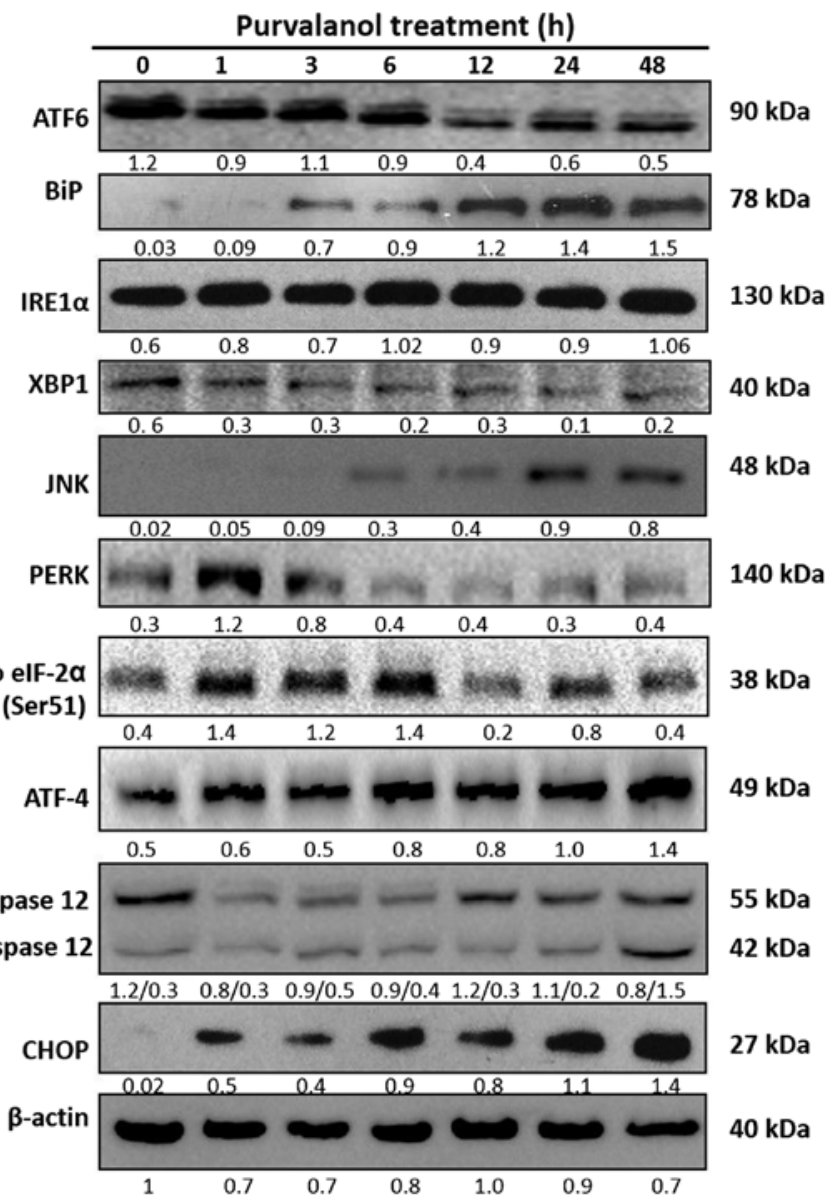

C Purvalanol treatment (h) Starvation
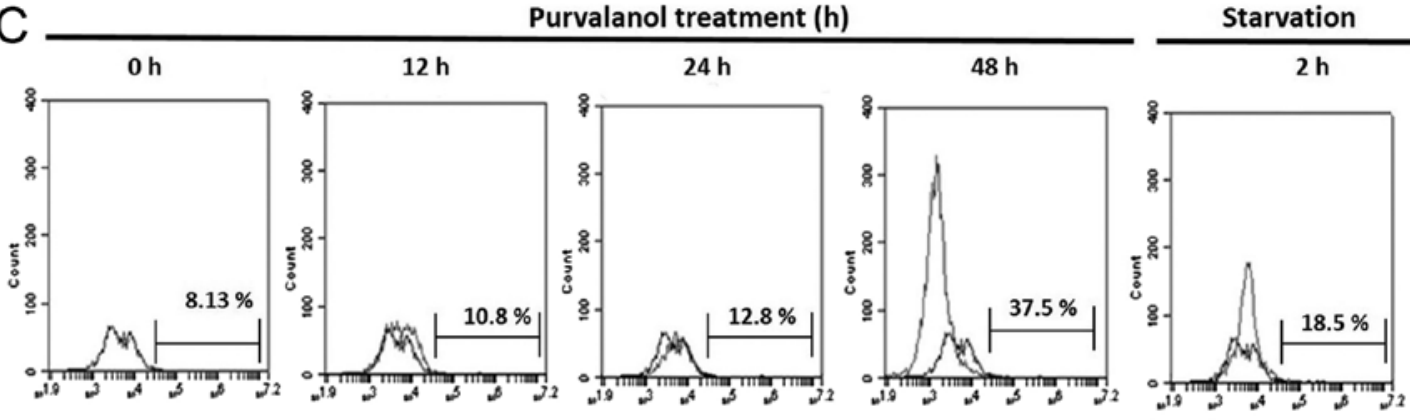

mCherry Fluorescence(FL-3)

Figure 3. Purvalanol triggers ER stress in a time-dependent manner. Following time-dependent purvalanol treatment, total proteins were isolated and separated on $12 \%$ SDS gel, transferred onto PVDF membranes and blotted with (A) PDI, calnexin, calreticulin, (B) ATF-6, BiP, IRE1a, PERK, XBP1, JNK, eIF-2a, ATF-4, caspase-12 and CHOP antibodies. GAPDH and $\beta$-actin were used as a loading control. (C) Cells (3x105) were transfected with the mCherry CHOP plasmid and following $24 \mathrm{~h}$, the cells were treated with $15 \mu \mathrm{M}$ purvalanol for 12, 24 and $48 \mathrm{~h}$. Purvalanol-induced CHOP activation was examined by FACS flow analysis at FL-3 channel. 

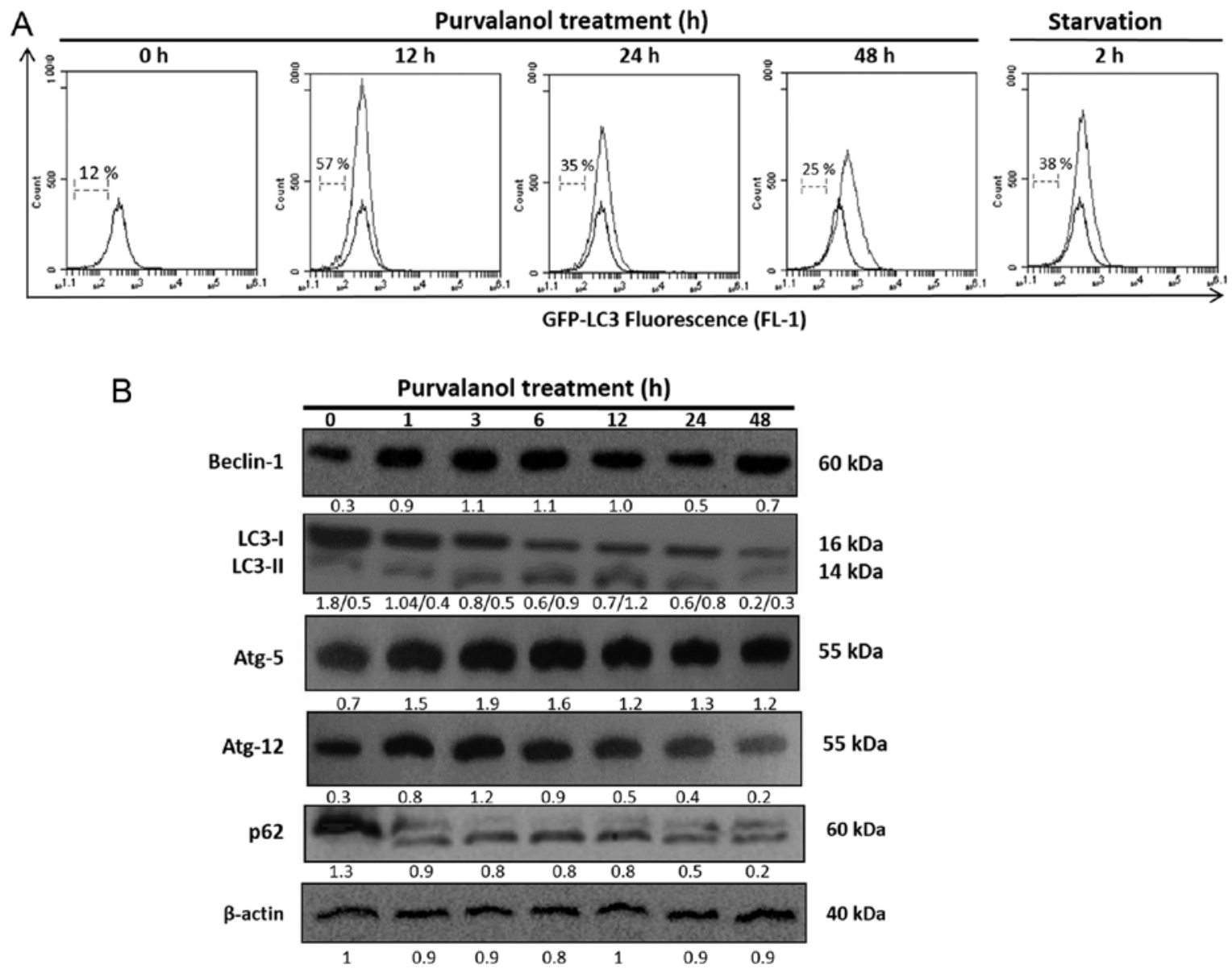

Figure 4. Purvalanol activates autophagy. (A) GFP-LC3 in purvalanol-treated HCT 116 colon cancer cells. Following a 24 h transfection of the HCT 116 colon cancer cells with the GFP-LC3 plasmid, the cells were treated with $15 \mu \mathrm{M}$ purvalanol for 12, 24 and $48 \mathrm{~h}$. Purvalanol induced LC3 degradations were examined by FACS flow analysis at FL-1 channel. (B) The effects of purvalanol on Beclin-1, LC3, Atg-5, Atg-12 and p62 gene expression profiles were determined by immunoblotting in HCT 116 colon cancer cells following 0-48 h purvalanol (15 $\mu \mathrm{M})$ treatments. $\beta$-actin was used as a loading control. GFP, green fluorescent protein.

was also upregulated following time-dependent purvalanol treatment. Late response of cells to purvalanol treatment related with ER stress was determined by the cleavage of ATF- 6 after $12 \mathrm{~h}$. CHOP, a transcriptional target of both cleaved ATF-6 and ATF-4, was found to be significantly upregulated following a $12 \mathrm{~h}$ purvalanol treatment (Fig. 3B). In order to examine the purvalanol-induced CHOP activation, we performed FACS flow analysis after transfection of the CHOP promoter (-649/+136) pmCherry-1 plasmid (Fig. 3C). According to FACS flow analysis, purvalanol-induced $\mathrm{CHOP}$ activation via ATF-4 transcriptional activity was determined after $48 \mathrm{~h}$.

Purvalanol-induced ER stress activates autophagy in HCT 116 colon cancer cells. To evaluate the effect of purvalanol on autophagic regulation related with its influence on ER membrane receptor activation, we examined the involvement of LC3 via GFP-LC3 plasmid transfection in the HCT 116 cells. According to FACS flow analysis, purvalanol induced GFP-LC3 intensity within a $12 \mathrm{~h}$ drug exposure and this effect was maintained for $24 \mathrm{~h}$ (Fig. 4A). Moreover, Beclin-1, Atg-5 and Atg-12 expression levels were upregulated; p62 degradation and LC3 cleavage were observed at early time-points following purvalanol treatment in the HCT 116 colon cancer cells (Fig. 4B).

Prolonged purvalanol treatment causes apoptotic cell death by modulating the Bcl-2 family members in HCT 116 colon cancer cells. The apoptotic induction due to purvalanol was determined by Cell Death ELISA assay. As shown in Fig. 5A, exposure of cells to $15 \mu \mathrm{M}$ purvalanol for 12,24 and $48 \mathrm{~h}$ induced apoptosis by 2.5-, 3.5- and 5.5-fold compared to the untreated control cells $(\mathrm{p}<0.05$ and $\mathrm{p}<0.001)$, respectively. The apoptotic induction of purvalanol was found to be caspase-dependent. As shown in Fig. 5B, caspase-7 and caspase- 3 were activated by causing PARP cleavage. As shown in Fig. 5C, $15 \mu \mathrm{M}$ purvalanol for 12, 24 and $48 \mathrm{~h}$ induced MMP loss by 75,55 and $40 \%$, respectively $(\mathrm{p}<0.05$ and $\mathrm{p}<0.001)$. To analyze the functional role of $\mathrm{Bcl}-2$ family members in mitochondria-mediated apoptosis due to purvalanol treatment, the modulation of the expression levels of anti- and pro-apoptotic proteins was examined in the HCT 116 cells by western blot analysis. Purvalanol downregulated Bcl-xL and Mcl-1 and upregulated Bik, Bad, Bid, Bad and PUMA protein expression levels (Fig. D). Therefore, we conclude that purvalanol induced mitochondria-mediated 
A
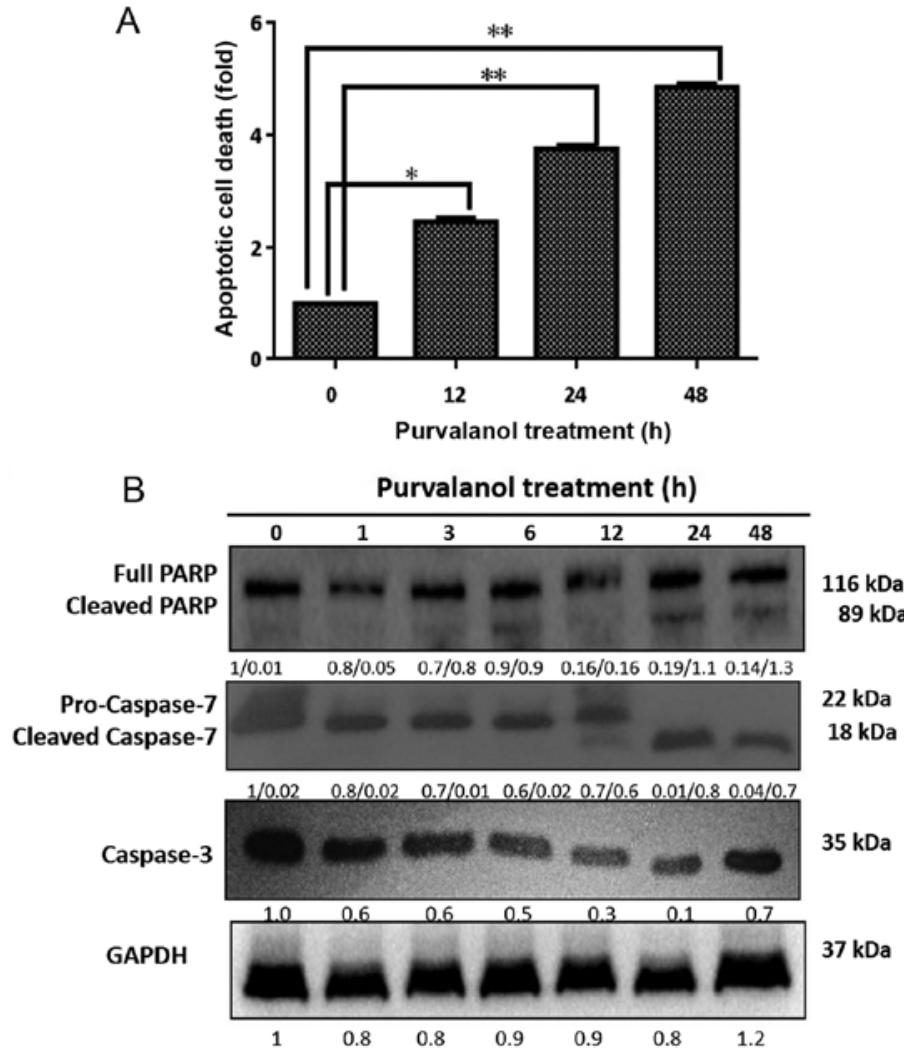

D
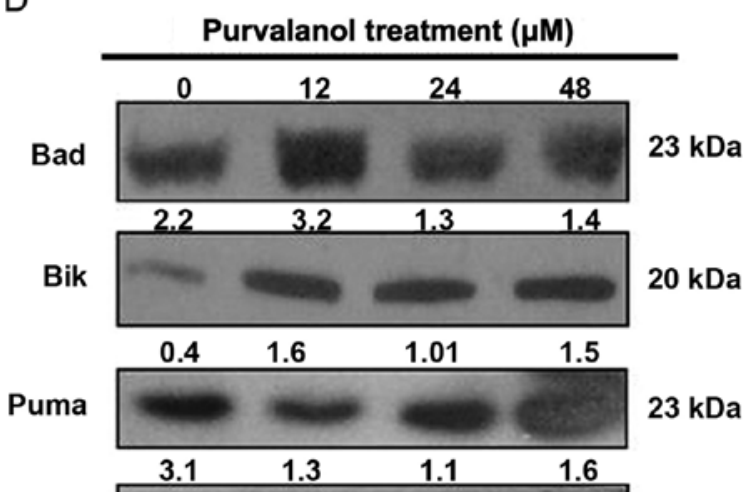

Bid

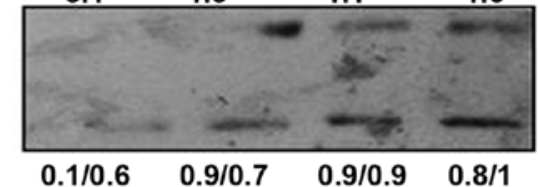

$22 \mathrm{kDa}$

$15 \mathrm{kDa}$

Mcl-1

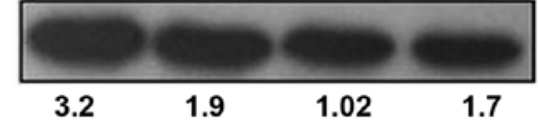

$35 \mathrm{kDa}$

C

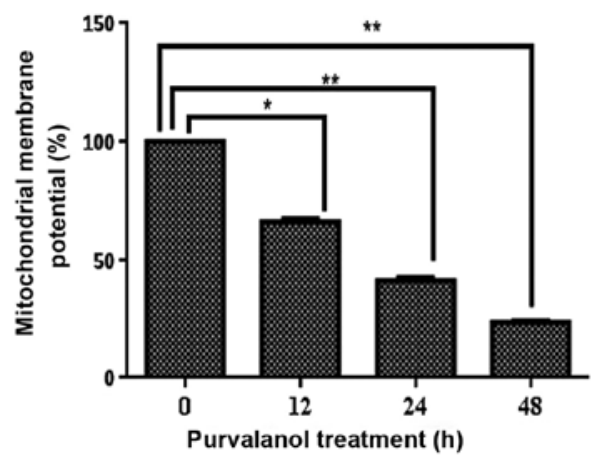

Bcl- $\mathbf{x}_{\mathbf{L}}$

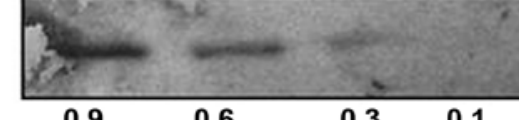

$30 \mathrm{kDa}$

$\beta$-actin

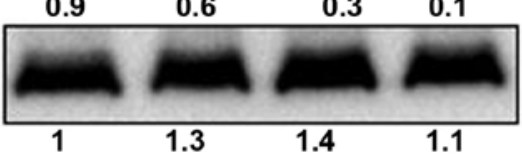

$40 \mathrm{kDa}$

Figure 5. Purvalanol induces apoptosis by modulating the expression of Bcl-2 family proteins. (A) Apoptotic cell death was determined by using Cell Death ELISA Plus assay following exposure of HCT 116 colon carcinoma cells to purvalanol. (B) Time-dependent PARP cleavage and caspase-3 and caspase-7 activation were determined by immunoblotting in the purvalanol-treated HCT 116 colon carcinoma cells. (C) The disruption of MMP loss was measured after DiOC6 staining using a fluorometer $(E x=485 \mathrm{~nm} ; E m=538 \mathrm{~nm})$. (D) Following time-dependent purvalanol treatment, total proteins were isolated and separated on $12 \%$ SDS gel, transferred onto PVDF membranes and blotted with Bad, Bik, Puma, Bid, Mcl-1, Bcl-xL antibodies. The columns represent the mean \pm SD of two independent trials with at least 2 replicates. Statistical difference was analyzed using an unpaired $\mathrm{t}$-test; ${ }^{*} \mathrm{p}<0.05,{ }^{* *} \mathrm{p}<0.001$. GAPDH and $\beta$-actin were used as a loading control.

apoptosis by activating caspases and modulating Bcl-2 family members.

\section{Discussion}

Dysregulation of molecular machinery of the cell cycle process plays an important role in tumor progression and malignancy (1). Thus, control of the cell cycle by pharmacological CDKIs, is believed to be an important therapeutic target for cancer therapy. CDKIs have been shown to be promising chemotherapeutic agents in various cancer types such as colon (7), prostate (5) and breast cancer (6). Purvalanol, a new generation CDKI, has been shown to cause cell cycle arrest at the $\mathrm{G} 2$ /M checkpoint of the cell cycle by inhibiting the ATP binding site of CDK1 and CDK2 (14) and to induce apoptosis through activating caspases and cytochrome- $c$ release in gastric cancer cells (15). In our previous study, we determined that $30 \mu \mathrm{M}$ purvalanol induced apoptotic cell death by modulating the expression of the Bcl-2 family members via activating polyamine catabolic metabolism in HCT 116 colon cancer cells (7). Another previous study from our laboratory showed that $25 \mu \mathrm{M}$ purvalanol induced apoptosis via activation of caspases, which led to dysfunction of MMP in MCF-7 breast cancer cells (6). A lower dose of purvalanol $(15 \mu \mathrm{M})$ used in this study also inhibited cell proliferation via cell cycle arrest and induced cell death through MMP loss 
(Figs. 1 and 2). Although a number of reports have demonstrated the molecular action of roscovitine, there are few research studies concerning purvalanol-induced apoptotic cell death. Thus, clarification of molecular targets of purvalanol treatment on apoptosis and autophagic mechanisms might increase the therapeutic efficiency of the drug.

During homeostatic conditions in eukaryotic cells, ER is essential in biosynthesis and signaling functions, and several resident chaperones, $\mathrm{Ca}^{2+}$ binding proteins and folding enzymes such as calnexin, calreticulin and protein disulfide isomerase (PDI) are known to monitor ER biological functions (16). It was shown that a lack of calnexin within the cell induced a resistant profile against ER stress-mediated apoptosis as it acts with caspase- 8 for Bap31 protein cleavage (17). In addition, although overexpression of calreticulin in HeLa cells was shown to enhance the sensitivity against ceramide-induced apoptosis (18), knockout of calreticulin increased the resistance phenotype (19). Moreover, silencing of calreticulin in bladder cancer cells suppressed cell proliferation, migration and attachment, whereas overexpression of calreticulin enhanced cell migration and attachment (20). Thus, in the present study, we determined that purvalanol induced UPR as a first response. Both PDI and calnexin expression profiles were upregulated following a $1 \mathrm{~h}$ purvalanol treatment and this effect was observed until $12 \mathrm{~h}$. In addition, calreticulin expression was downregulated at early time-points following purvalanol treatment which modulated $\mathrm{Ca}^{2+}$ levels and cell adhesion (Fig. 3A). These results suggest that purvalanol might first trigger ER stress via ER chaperone activation in HCT 116 colon cancer cells.

Accumulation of unfolded or misfolded proteins in the ER lumen during hypoxia, oxidative injury, a high-fat diet or viral infections was found to induce various intracellular signaling pathways via activation of receptors localized on the ER membrane (9). During ER stress, disassociation of ER membrane receptors from their ligand BiP caused receptor-mediated nuclear activation of various transcription factors such as ATF-6, ATF-4 and CHOP (12). ER stress- activated ER membrane receptor, ATF-6 p90, is activated following $\mathrm{BiP}$ disassociation and cleavage to form ATF-6 p50, a regulatory protein of X-box binding protein 1 (XBP-1) mRNA (21). Cleaved and activated ATF-6 p50 protein translocates to the nucleus and triggers UPR target genes such as BiP and XBP1 (22). Similar to this finding, N-butylidenephthalide was shown to induce ER-stress by triggering ATF-6 cleavage and BiP upregulation within $6 \mathrm{~h}$ after drug exposure in $\mathrm{LNCaP}$ and $\mathrm{PC} 3$ prostate cancer cell lines (23). Both ATF-6 and IRE1 $\alpha$ trigger the transcription of ER chaperones during ER stress conditions via acting on XBP1 mRNA (24). Moreover, IRE1 $\alpha$ interaction with TRAF-2 triggers apoptotic cell death via JNK activation (25). Although 6-shogaol induced apoptosis without any significant effect on IRE1 $\alpha$ in SMMC-7721 hepatocellular carcinoma cells (26), 20-O-( $\beta$-D-glucopyranosyl)-20(S)-protopanaxadiol activated the IRE1 $\alpha$ phosphorylation and splicing of XBP1 in HT29 human colon cancer cells (27). In addition, upregulation of IRE-1 $\alpha$ was determined after a 6 -h $\mathrm{N}$-butylidenephthalide treatment in prostate cancer cell lines (23). In the present study, although we demonstrated upregulation of IRE-1 $\alpha$ expression and an increase in XBP1 splicing, a significant upregulation of JNK expression was observed after a 24-h purvalanol treatment (Fig. 3B). Concominantly, purvalanol induced apoptotic cell death via activation of caspase-3 and caspase-7 and PARP cleavage (Fig. 5B). Thus, we conclude that short-term purvalanol treatment induces ATF-6-mediated ER stress and long-term purvalanol induces apoptotic cell death through activation of JNK in HCT 116 colon cancer cells.

The third ER membrane receptor, PERK, is dimerized, and auto-phosphorylation of itself activates the phosphorylation of eIF-2 $\alpha$ that attenuates protein translation (11). PERK activation and eIF-2 $\alpha$ phosphorylation were determined after a 6 -h 20-O-( $\beta$-D-glucopyranosyl)-20(S)-protopanaxadiol treatment in HT29 human colon cancer cells (27). 6-shogaol induced apoptosis via activation of PERK and its downstream target eIF-2 $\alpha$ in SMMC-7721 hepatocellular carcinoma cells (26). In addition, luteolin-induced eIF-2 $\alpha$ phosphorylation within a $2 \mathrm{~h}$ drug treatment triggered the ER stress-mediated apoptosis in NCI-H460 lung carcinoma cells (28). We determined that PERK expression was upregulated only after a $1 \mathrm{~h}$ purvalanol treatment and phosphorylation of eIF-2 $\alpha$ was also observed during 1-6 h of purvalanol treatment (Fig. 3B). Purvalanol might induce UPR and attenuate protein translation at early time-points in HCT 116 cells by activating the PERK/eIF-2 $\alpha / \mathrm{ATF}-4$ signaling axis.

$\mathrm{CHOP}$, is a key ER stress-induced transcription factor and transcription activation is through ATF-6 and ATF-4 (29). Deficiency of CHOP protected cells from ER-induced apoptotic cell death (30) and overexpression of CHOP stimulated cell cycle arrest and apoptosis (31). Activated CHOP expression has been implicated to repress anti-apoptotic Bcl-2 protein (32) and induce apoptotic cell death by activating Bim (33). We showed that CHOP expression was significantly upregulated after a $6 \mathrm{~h}$ purvalanol treatment and this effect was increased in a time-dependent manner (Fig. 3B). Moreover, when we analyzed the activation of CHOP via the CHOP promoter $(-649 /+136)$ inserted mCherry expression plasmid, mCherry expression was found to be elevated following a $48 \mathrm{~h}$ purvalanol treatment (Fig. 3C). CHOP-mediated ER stress-induced apoptotic cell death occurred after a $48 \mathrm{~h}$ purvalanol treatment in the HCT 116 colon cancer cells.

ER stress-induced autophagy is assumed to be activated as an alternative way to degradate accumulated unfolded/misfolded protein aggregates instead of the proteasome degradation system (12). Both IRE1 $\alpha$ and PERK pathways were demonstrated to be associated with ER stressinduced autophagy regulation in cancer cells (34). In contrary, other studies reported that only PERK-eIF- $2 \alpha$ signaling was involved in autophagy induction by ER stress (35). Autophagy, an evolutionarily conserved process, characterized by massive degradation of cytosolic contents initiates the fusion of autophagosomes to endosomes and lysosomes, which engulf cytoplasmic contents within a double-membrane vacuole (36). This physiological process is carried out through interaction of various molecules such as Bcl-2, Beclin-1, Atg-5 and Atg-12 (37). During autophagic induction, LC3-I (16 kDa) is cleaved to form LC3-II (14 kDa) that is involved in autophagic vacuole membrane formation by interacting with cytoplasmic protein p62 (38). As autophagy is assumed to be a cell survival mechanism against chemotherapeutic drugs in cancer cells, inhibition of autophagy by specific inhibitors induced drug- 
mediated apoptotic cell death in prostate (39), breast (40) and colon (41) cancer cells. Moreover, in NCI-H460 lung carcinoma cells, although luteolin induced ER stress activated apoptosis, autophagy was shown to be activated and inhibition of autophagy induced apoptotic cell death (28). Thus, in our present study we determined that another CDKI, purvalanol, induced autophagy induction by upregulation of Beclin-1, Atg-5, Atg-12 protein expression and LC3-II formation during a 6-12 h purvalanol treatment (Fig. 4B) only after PERK/ eIF- $2 \alpha$ induced ER stress.

The inactive state of ER membrane receptors can be stimulated by slight ER stress conditions leading to translation inhibition. Under this situation, autophagy induction could occur as a cell protection mechanism. However, prolonged ER stress can also result in apoptotic cell death through various molecular key players such as caspase-12, JNK and CHOP (42). Our previous studies found that long-term exposure of purvalanol triggered mitochondrial-mediated and caspase-dependent apoptotic cell death in MCF-7 cells following treatment with $25 \mu \mathrm{M}$ purvalanol (6) and in HCT 116 colon cancer cells after of $30 \mu \mathrm{M}$ purvalanol (7). In the present study, a lower dose of purvalanol for a long-term exposure triggered caspase-dependent apoptotic cell death via modulation of Bcl-2 family members and this effect was significant after a $24 \mathrm{~h}$ purvalanol treatment in the HCT 116 colon cancer cells (Fig. 5A-D). Finally, we conclude that purvalanol induced ER stress-mediated autophagy as a first response in HCT 116 colon cancer cells against purvalanol. Prolonged ER stress activated both CHOP and JNK- mediated apoptotic cell death.

\section{Acknowledgements}

The present study was supported by the Istanbul Kultur University Scientific Projects Support Center and the TUBITAK Scientific Projects Support Center (2209 program).

\section{References}

1. Harper JW and Adams PD: Cyclin-dependent kinases. Chem Rev 101: 2511-2526, 2001.

2. Knockaert M, Greengard P and Meijer L: Pharmacological inhibitors of cyclin-dependent kinases. Trends Pharmacol Sci 23: 417-425, 2002.

3. Gray N, Détivaud L, Doerig C and Meijer L: ATP-site directed inhibitors of cyclin-dependent kinases. Curr Med Chem 6: 859-875, 1999 .

4. Gray NS, Wodicka L, Thunnissen AM, Norman TC, Kwon S, Espinoza FH, Morgan DO, Barnes G, Le Clerc S, Meijer L, et al: Exploiting chemical libraries, structure, and genomics in the search for kinase inhibitors. Science 281: 533-538, 1998.

5. Arisan ED, Obakan P, Coker-Gurkan A, Calcabrini A, Agostinelli E and Unsal NP: CDK inhibitors induce mitochondria-mediated apoptosis through the activation of polyamine catabolic pathway in LNCaP, DU145 and PC3 prostate cancer cells. Curr Pharm Des 20: 180-188, 2014.

6. Obakan P, Arisan ED, Özfiliz P, Çoker-Gürkan A and Palavan-Ünsal N: Purvalanol A is a strong apoptotic inducer via activating polyamine catabolic pathway in MCF-7 estrogen receptor positive breast cancer cells. Mol Biol Rep 41: 145-154, 2014.

7. Gürkan AC, Arisan ED, Obakan P and Palavan-Ünsal N: Inhibition of polyamine oxidase prevented cyclin-dependent kinase inhibitor-induced apoptosis in HCT 116 colon carcinoma cells. Apoptosis 18: 1536-1547, 2013.

8. Kaufman RJ: Stress signaling from the lumen of the endoplasmic reticulum: coordination of gene transcriptional and translational controls. Genes Dev 13: 1211-1233, 1999.
9. Schroder M and Kaufman RJ: ER stress and the unfolded protein response. Mutat Res 569: 29-63, 2005.

10. Yoshida H: Molecular biology of the ER stress response. Seikagaku 76: 617-630, 2004 (In Japanese).

11. Harding HP, Zhang Y, Bertolotti A, Zeng H and Ron D: Perk is essential for translational regulation and cell survival during the unfolded protein response. Mol Cell 5: 897-904, 2000.

12. Ogata M, Hino S, Saito A, Morikawa K, Kondo S, Kanemoto S, Murakami T, Taniguchi M, Tanii I, Yoshinaga K, et al: Autophagy is activated for cell survival after endoplasmic reticulum stress. Mol Cell Biol 26: 9220-9231, 2006.

13. Morishima N, Nakanishi K, Takenouchi H, Shibata T and Yasuhiko Y: An endoplasmic reticulum stress-specific caspase cascade in apoptosis. Cytochrome $c$-independent activation of caspase-9 by caspase-12. J Biol Chem 277: 34287-34294, 2002.

14. Iizuka D, Inanami O, Kashiwakura I and Kuwabara M: Purvalanol A enhances cell killing by inhibiting up-regulation of CDC2 kinase activity in tumor cells irradiated with high doses of $\mathrm{X}$ rays. Radiat Res 167: 563-571, 2007.

15. Villerbu N, Gaben AM, Redeuilh G and Mester J: Cellular effects of purvalanol A: a specific inhibitor of cyclin-dependent kinase activities. Int J Cancer 97: 761-769, 2002.

16. Molinari M, Eriksson KK, Calanca V, Galli C, Cresswell P, Michalak $\mathrm{M}$ and Helenius A: Contrasting functions of calreticulin and calnexin in glycoprotein folding and ER quality control. Mol Cell 13: 125-135, 2004.

17. Zuppini A, Groenendyk J, Cormack LA, Shore G, Opas M, Bleackley RC and Michalak M: Calnexin deficiency and endoplasmic reticulum stress-induced apoptosis. Biochemistry 41: 2850-2858, 2002.

18. Pinton P, Ferrari D, Rapizzi E, Di Virgilio F, Pozzan T and Rizzuto R: The $\mathrm{Ca}^{2+}$ concentration of the endoplasmic reticulum is a key determinant of ceramide-induced apoptosis: significance for the molecular mechanism of Bcl-2 action. EMBO J 20: 2690-2701, 2001.

19. Nakamura K, Bossy-Wetzel E, Burns K, Fadel MP, Lozyk M, Goping IS, Opas M, Bleackley RC, Green DR and Michalak M: Changes in endoplasmic reticulum luminal environment affect cell sensitivity to apoptosis. J Cell Biol 150: 731-740, 2000.

20. Lu YC, Chen CN, Wang B, Hsu WM, Chen ST, Chang KJ, Chang $\mathrm{CC}$ and Lee $\mathrm{H}$ : Changes in tumor growth and metastatic capacities of J82 human bladder cancer cells suppressed by down-regulation of calreticulin expression. Am J Pathol 179: 1425-1433, 2011

21. Yoshida H, Haze K, Yanagi H, Yura T and Mori K: Identification of the cis-acting endoplasmic reticulum stress response element responsible for transcriptional induction of mammalian glucose-regulated proteins. Involvement of basic leucine zipper transcription factors. J Biol Chem 273: 33741-33749, 1998.

22. Haze K, Yoshida H, Yanagi H, Yura T and Mori K: Mammalian transcription factor ATF6 is synthesized as a transmembrane protein and activated by proteolysis in response to endoplasmic reticulum stress. Mol Biol Cell 10: 3787-3799, 1999.

23. Chiu SC, Chen SP, Huang SY, Wang MJ, Lin SZ, Harn HJ and Pang CY: Induction of apoptosis coupled to endoplasmic reticulum stress in human prostate cancer cells by n-butylidenephthalide. PLoS One 7: e33742, 2012.

24. Yoshida H, Okada T, Haze K, Yanagi H, Yura T, Negishi M and Mori K: Endoplasmic reticulum stress-induced formation of transcription factor complex ERSF including NF-Y (CBF) and activating transcription factors 6alpha and 6beta that activates the mammalian unfolded protein response. Mol Cell Biol 21: 1239-1248, 2001.

25. Urano F, Bertolotti A and Ron D: IRE1 and efferent signaling from the endoplasmic reticulum. J Cell Sci 113: 3697-3702, 2000.

26. Hu R, Zhou P, Peng YB, Xu X, Ma J, Liu Q, Zhang L, Wen XD, Qi LW, Gao N, et al: 6-Shogaol induces apoptosis in human hepatocellular carcinoma cells and exhibits anti-tumor activity in vivo through endoplasmic reticulum stress. PLoS One 7: e39664, 2012.

27. Zhang R, Chung Y, Kim HS, Kim DH, Kim HS, Chang WY and Hyun JW:20-O-(beta-D-glucopyranosyl)-20(S)-protopanaxadiol induces apoptosis via induction of endoplasmic reticulum stress in human colon cancer cells. Oncol Rep 29: 1365-1370, 2013.

28. Park SH, Park HS, Lee JH, Chi GY, Kim GY, Moon SK, Chang YC, Hyun JW, Kim WJ and Choi YH: Induction of endoplasmic reticulum stress-mediated apoptosis and non-canonical autophagy by luteolin in NCI-H460 lung carcinoma cells. Food Chem Toxicol 56: 100-109, 2013. 
29. Ma Y, Brewer JW, Diehl JA and Hendershot LM: Two distinct stress signaling pathways converge upon the CHOP promoter during the mammalian unfolded protein response. J Mol Biol 318 1351-1365, 2002.

30. Zinszner H, Kuroda M, Wang X, Batchvarova N, Lightfoot RT, Remotti H, Stevens JL and Ron D: CHOP is implicated in programmed cell death in response to impaired function of the endoplasmic reticulum. Genes Dev 12: 982-995, 1998.

31. Barone MV, Crozat A, Tabaee A, Philipson L and Ron D: CHOP (GADD153) and its oncogenic variant, TLS-CHOP, have opposing effects on the induction of G1/S arrest. Genes Dev 8: 453-464, 1994.

32. McCullough KD, Martindale JL, Klotz LO, Aw TY and Holbrook NJ: Gadd153 sensitizes cells to endoplasmic reticulum stress by down-regulating $\mathrm{Bcl} 2$ and perturbing the cellular redox state. Mol Cell Biol 21: 1249-1259, 2001.

33. Puthalakath H, O'Reilly LA, Gunn P, Lee L, Kelly PN, Huntington ND, Hughes PD, Michalak EM, McKimm-Breschkin J, Motoyama N, et al: ER stress triggers apoptosis by activating BH3-only protein Bim. Cell 129: 1337-1349, 2007.

34. Vidal RL and Hetz C: Crosstalk between the UPR and autophagy pathway contributes to handling cellular stress in neurodegenerative disease. Autophagy 8: 970-972, 2012.

35. Carra S, Brunsting JF, Lambert H, Landry J and Kampinga $\mathrm{HH}$ : HspB8 participates in protein quality control by a non-chaperone-like mechanism that requires eIF2\{alpha\} phosphorylation. J Biol Chem 284: 5523-5532, 2009.
36. Martinet W, Agostinis P, Vanhoecke B, Dewaele M and De Meyer GR: Autophagy in disease: a double-edged sword with therapeutic potential. Clin Sci (Lond) 116: 697-712, 2009.

37. $\mathrm{Ku} \mathrm{B}$, Woo JS, Liang C, Lee KH, Hong HS, E X, Kim KS, Jung JU and Oh BH: Structural and biochemical bases for the inhibition of autophagy and apoptosis by viral BCL-2 of murine gamma-herpesvirus 68. PLoS Pathog 4: e25, 2008.

38. Pankiv S, Clausen TH, Lamark T, Brech A, Bruun JA, Outzen H, Øvervatn A, Bjørkøy G and Johansen T: p62/SQSTM1 binds directly to Atg8/LC3 to facilitate degradation of ubiquitinated protein aggregates by autophagy. J Biol Chem 282: 24131-24145, 2007.

39. Kumar D, Shankar S and Srivastava RK: Rottlerin induces autophagy and apoptosis in prostate cancer stem cells via PI3K/Akt/mTOR signaling pathway. Cancer Lett 343: 179-189, 2014.

40. Cui Q, Tashiro S, Onodera S, Minami M and Ikejima T: Autophagy preceded apoptosis in oridonin-treated human breast cancer MCF-7 cells. Biol Pharm Bull 30: 859-864, 2007.

41. Li J, Hou N, Faried A, Tsutsumi S, Takeuchi T and Kuwano H: Inhibition of autophagy by 3-MA enhances the effect of 5-FUinduced apoptosis in colon cancer cells. Ann Surg Oncol 16: 761-771, 2009.

42. Schönthal AH: Endoplasmic reticulum stress and autophagy as targets for cancer therapy. Cancer Lett 275: 163-169, 2009. 